\title{
The relationship between Helicobacter pylori infection and promoter polymorphism of the Nrf2 gene in chronic gastritis
}

\author{
TOMIYASU ARISAWA, TOMOMITSU TAHARA, TOMOYUKI SHIBATA, MITSUO NAGASAKA, \\ MASAKATSU NAKAMURA, YOSHIO KAMIYA, HIROSHI FUJITA, SHIN HASEGAWA, \\ TAMAKI TAKAGI, FANG-YU WANG, ICHIRO HIRATA and HIROSHI NAKANO \\ Department of Gastroenterology, Fujita Health University School of Medicine, 1-98, \\ Dengakugakubo, Kutsukake-cho, Toyoake 470-1192, Japan
}

Received July 31, 2006; Accepted September 27, 2006

\begin{abstract}
The transcription factor Nrf2 regulates the expression of detoxifying and antioxidant genes. Three polymorphisms of the Nrf2 gene have been reported. We attempted to clarify the relationship between Nrf2 gene polymorphism and chronic gastritis in a Japanese population. The study was performed in 159 patients with no evidence of gastric malignancy on upper gastrointestinal endoscopy (mean age, 62.03 years; male:female ratio, 102:57; peptic ulcer diseases in 69 patients, and Helicobacter pylori (H. pylori) positivity in $73.0 \%$ ). We employed the PCR-SSCP method to detect gene polymorphisms using DNA extracted from peripheral blood cells or from antral biopsy specimens obtained by endoscopy. The severity of the histological chronic gastritis in antral biopsy specimens was classified according to the updated Sydney system. Although the frequencies of the $\operatorname{SNP}(-686)$ and $\operatorname{SNP}(-650)$ A alleles were decreased in subjects with peptic ulcers or severe mucosal atrophy, no significant differences were seen. However, the number of $-686 \mathrm{G}$ alleles was correlated with both neutrophil activity and mononuclear cell infiltration ( $\mathrm{p}=0.036$ and $\mathrm{p}=0.010$, respectively), while the $-650 \mathrm{C} / \mathrm{C}$ genotype was an independent risk factor for mononuclear cell infiltration ( $p=0.021$ by ANOVA). In addition, both the number of -686 $\mathrm{G}$ alleles and the $-650 \mathrm{C} / \mathrm{C}$ genotype showed an interaction with $H$. pylori infection to promote the infiltration of mononuclear cells ( $\mathrm{p}=0.037$ by ANCOVA and $\mathrm{p}=0.041$ by ANOVA, respectively). Nrf2 promoter polymorphisms are significantly associated with the development of gastric mucosal inflammation, either independently or by interacting with $H$. pylori infection.
\end{abstract}

Correspondence to: Dr Tomiyasu Arisawa, Department of Gastroenterology, Fujita Health University School of Medicine, 1-98, Dengakugakubo, Kutsukake-cho, Toyoake 470-1192, Japan

E-mail: tarisawa@fujita-hu.ac.jp

Key words: nuclear factor-erythroid 2-related factor 2, promoter polymorphism, chronic gastritis, Helicobacter pylori

\section{Introduction}

Infection with Helicobacter pylori (H. pylori) usually leads to persistent colonization and chronic gastric inflammation. Infected patients can develop multifocal atrophic gastritis, intestinal metaplasia, dysplasia, and distal gastric carcinoma (1-3). However, there are marked differences in the extent of inflammation among $H$. pylori-infected patients, so clinical consequences only develop in a small subgroup. The course of $H$. pylori infection is influenced by bacterial virulence factors, as well as by genetic predisposition and host immunity. That is, in addition to bacterial factors, unknown host factors seem to influence the inflammatory response and the development of severe gastritis. Inflammation induced by $H$. pylori is implicated in gastric mucosal damage and is characterized by severe granulocytic and lymphocytic infiltration $(4,5)$. Although the $\mathrm{T}$ helper cell response to $H$. pylori is considered to be dependent on type 1 helper (Th1) cells, the factors influencing this immune response to $H$. pylori infection are largely unknown. Important cytokines that are related to Th1-mediated responses and are upregulated during chronic $H$. pylori infection include interferon- $\gamma$, tumor necrosis factor, and interleukin-1ß (6-9). It has been reported that the genes encoding cytokines have various polymorphisms, which are considered to alter gene transcription and thereby influence the inflammatory response $(10,11)$. In fact, there have been several reports about the association between cytokine gene polymorphisms and gastric inflammation during $H$. pylori infection (12-14).

Another important factor that influences $H$. pyloriinduced gastric inflammation is oxidative stress (15). Reactive oxygen species (ROS) are believed to be involved in promoting inflammation and in regulating the expression of oncogenes (16). Enhanced ROS production has been demonstrated in endoscopic biopsy samples from the duodenum and stomach of $H$. pylori-infected patients $(17,18)$. Thus, there seems to be no doubt that ROS have an important role in the development of gastric inflammation induced by H. pylori infection. On the other hand, studies have suggested that nuclear factor-erythroid 2-related factor 2 (Nrf2) is an important regulator of genes induced by oxidative stress, such as heme oxygenase-1 and peroxiredoxin 1 (19). In addition, susceptibility to hyperoxia is tightly linked to the Nrf2 locus (20). Furthermore, Nrf2 null mice were found to 
be highly susceptible to hyperoxic lung injury (21), and it was also reported that the impaired defenses against the oxidative stress of these mice showed a substantially decreased clearance of ROS (22). More recently, three polymorphisms of the promoter region (positions, -686, -684, and -650) of the human Nrf2 gene were identified (23). This study did not reveal a close connection between the risk of inflammatory diseases and these polymorphisms, yet further examination of the link between Nrf2 polymorphisms and oxidative stress-related diseases is important.

In the present study, we investigated the association between Nrf2 polymorphisms and chronic gastric inflammation in a Japanese population, as well as the interaction between these polymorphisms and $H$. pylori infection.

\section{Materials and methods}

Clinical samples and extraction of DNA. The study population comprised 159 patients with no neoplastic lesions, who were enrolled at the Endoscopy Center of Fujita Health University Hospital. All of the patients underwent upper gastrointestinal endoscopy with biopsies being taken from the antral mucosa. One part of each specimen was fixed in $10 \%$ buffered formalin and embedded in paraffin, while the other part was immediately frozen and stored at $-80^{\circ} \mathrm{C}$.

All histological diagnoses were made at the Division of Pathology of our hospital. The severity of chronic gastritis was also classified according to the updated Sydney system (24) by a pathologist who had no access to clinical information. According to the severity of gastric mucosal atrophy, the subjects were divided into the following 3 groups: the nonatrophy (NA) group (atrophy score $=0$ and metaplasia score $=0$ ), the severe atrophy (SA) group (atrophy score $\geq 2$ or metaplasia score $\geq 2$ ), and the mild atrophy (MA) group (all others). Patients with severe systemic diseases were excluded.

Genomic DNA was isolated from the frozen specimens by digestion using proteinase $\mathrm{K}$. The $H$. pylori infection status was assessed by serology, histological examination, or the urea breath test. Patients were diagnosed as having infection when at least one of the diagnostic tests was positive.
The Ethics Committee of Fujita Health University School of Medicine approved the protocol, and written informed consent was obtained from all of the participating subjects.

Genotyping of Nrf2 polymorphisms. Nrf2 polymorphisms were genotyped by PCR-SSCP. We employed the nested PCR reaction because the quality of PCR-SSCP is dependent on the purity of the PCR reactants. The primer sequences are shown in Table I. The first PCR was carried out using the NRF2F and NRF2R primer pair in a volume of $20 \mu 1$ containing $0.1 \mu \mathrm{g}$ of genomic DNA. The DNA was denatured at $95^{\circ} \mathrm{C}$ for $5 \mathrm{~min}$, followed by 35 cycles at $95^{\circ} \mathrm{C}$ for $30 \mathrm{sec}, 62^{\circ} \mathrm{C}$ for $40 \mathrm{sec}$, and $72^{\circ} \mathrm{C}$ for $60 \mathrm{sec}$, with final extension at $72^{\circ} \mathrm{C}$ for $5 \mathrm{~min}$. The second PCR was carried out in a volume of $20 \mu \mathrm{l}$ containing $2 \mu \mathrm{l}$ of the first PCR product diluted 100-fold with distilled water as the sample and two primer pairs (NRF2-AF, -AR and NRF2-BF, -BR for -686 , -684 and -650 , respectively). After denaturation at $95^{\circ} \mathrm{C}$ for $5 \mathrm{~min}, 35 \mathrm{PCR}$ cycles were performed $\left(95^{\circ} \mathrm{C}\right.$ for $15 \mathrm{sec}, 62^{\circ} \mathrm{C}$ for $30 \mathrm{sec}$, and $72^{\circ} \mathrm{C}$ for $45 \mathrm{sec}$ ), followed by a final extension at $72^{\circ} \mathrm{C}$ for $5 \mathrm{~min}$. In the second PCR, other reverse primers (NRF2-AAG, -AAA, -AGG, and -AGA) and forward primers (NRF2-BA and -BC) were also used to create a positive control DNA fragment. Both PCR reactions were performed using EX Taq (Takara Bio Inc., Shiga, Japan).

Then $2 \mu \mathrm{l}$ of the second PCR product was denatured with $10 \mu 1$ of formamide (Sigma-Aldrich Co., St. Louis, MO, USA) at $90^{\circ} \mathrm{C}$ for $5 \mathrm{~min}$. SSCP was carried out at $5^{\circ} \mathrm{C}$ or $18^{\circ} \mathrm{C}$ using a GenePhor DNA separation system with GeneGel Excel 12.5/24 (Amersham Biosciences Corp., USA), after which the denatured single-strand DNA bands were detected using a DNA silver staining kit (Amersham Biosciences Corp.).

Statistical analysis. Associations were analyzed by the Mann-Whitney U test for age and the Chi-square test for gender and H. pylori positivity. The odds ratio (OR) and $95 \%$ confidence intervals (CI) were estimated by logistic regression analysis using the number of $-686 \mathrm{G}$ alleles or $-650 \mathrm{C}$ alleles as a covariate after adjustment for gender and $H$. pylori infection status. The interactions between $H$. pylori infection

Table I. Primer sequences for PCRs.

\begin{tabular}{llll}
\hline 1st PCR & NRF2F & forward & 5'-AAACGATTACAGCATGTTGTGGT-3' \\
& NRF2R & reverse & 5'-TGATTTGGAGTTGCAGAACCTT-3' \\
2nd PCR & NRF2-AF & forward & 5'-GCTCTGGGTGGGCAATACTG-3' \\
& NRF2-AR & reverse & 5'-CGCAGTCACCCTGAACGC-3' \\
& NRF2-BF & forward & 5'-TGACTGCGAACACGAGCTG-3' \\
& NRF2-BR & reverse & 5'-GGCTAAAGATTTGGACCCAGAC-3' \\
Positive control & NRF2-AAG & reverse & 5'-CGCAGTCACCCTGAACGCCCTCC-3' \\
& NRF2-AAA & reverse & 5'-CGCAGTCACCCTGAACGCTCTCC-3' \\
& NRF2-AGG & reverse & 5'-CGCAGTCACCCTGAACGCCCCCC-3' \\
& NRF2-AGA & reverse & 5'-CGCAGTCACCCTGAACGCTCCCC-3' \\
& NRF2-BA & forward & 5'-TGACTGCGAACACGAGCTGCCGGAG-3' \\
& NRF2-BC & forward & 5'-TGACTGCGAACACGAGCTGCCGGCG-3' \\
& &
\end{tabular}

Bold characters, mismatched bases in position $-686,-684$, and -650 . 
Table II. Characteristics of subjects.

\begin{tabular}{lrccc}
\hline & $\mathrm{n}$ & Mean age \pm SD & Male:Female & HP-positive rate \\
\hline Total & 159 & $62.03 \pm 13.03$ & $102: 57$ & $73.0 \%$ \\
Non-ulcer & 90 & $61.17 \pm 12.29$ & $44: 46$ & $61.1 \%$ \\
Peptic ulcer & 69 & $63.16 \pm 13.95$ & $58: 11^{\mathrm{a}}$ & $88.4 \% \%^{\mathrm{b}}$ \\
NA & 43 & $58.81 \pm 14.00^{\mathrm{c}}$ & $20: 23^{\mathrm{d}}$ & $25.6 \% \%^{\mathrm{f}}$ \\
MA & 60 & $60.88 \pm 14.40$ & $0: 25^{\mathrm{e}}$ & $83.3 \% \%^{\mathrm{g}}$ \\
SA & 56 & $65.73 \pm 9.60$ & $47: 9$ & $98.2 \%$ \\
\hline
\end{tabular}

NA, non-atrophy; MA, mild atrophy; SA, severe atrophy. ${ }^{a} \mathrm{p}<0.0001,{ }^{b} \mathrm{p}=0.0001$ vs non-ulcer, ${ }^{c} \mathrm{p}<0.0001$ vs $\mathrm{SA},{ }^{\mathrm{d}} \mathrm{p}<0.0001,{ }^{\mathrm{e}} \mathrm{p}=0.0008$ vs $\mathrm{SA},{ }^{\mathrm{f}} \mathrm{p}<0.0001$ vs MA or $\mathrm{SA}$ and ${ }^{\mathrm{g}} \mathrm{p}=0.0063$ vs $\mathrm{SA}$.

A

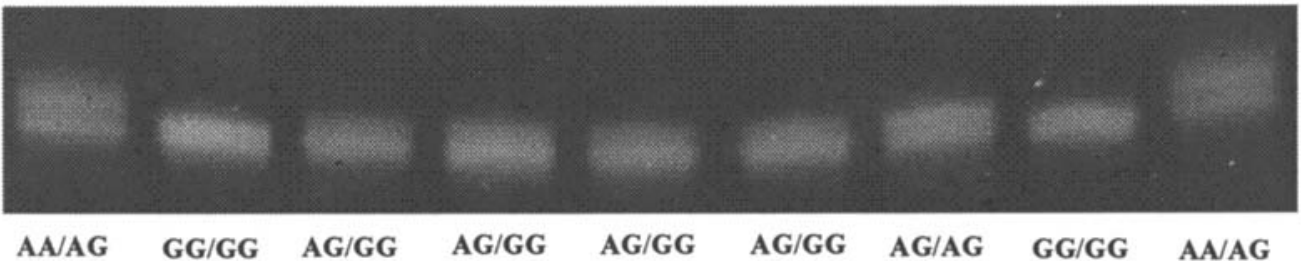

B

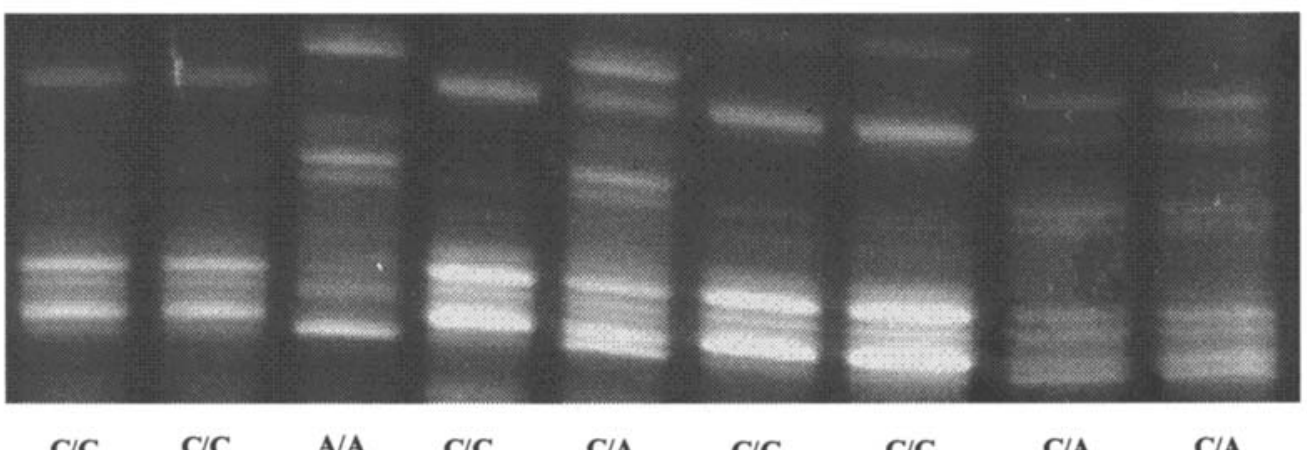

Figure 1. PCR-SSCP images. (A) Identification to bases in positions -686 and -684 using clinical samples. AA, -686A and -684A; AG, -686A and -684G; $\mathrm{GG},-686 \mathrm{G}$ and $-684 \mathrm{G}$. There was no GA allele in all cases. (B) Identification to base in position -650 .

status and Nrf2 polymorphisms with respect to the activity and inflammation scores were analyzed by ANOVA or ANCOVA using the number of $-686 \mathrm{G}$ alleles as a covariate. The Mann-Whitney $U$ test and linear regression analysis were employed to assess the association between Nrf2 polymorphisms and the updated Sydney system scores. For all analyses, the level of significance was set at $\mathrm{p}<0.05$.

\section{Results}

Subjects. A total of 159 subjects participated in this study. Their characteristics are summarized in Table II. Sixty-nine of the 159 subjects had gastric or duodenal ulcers. There was no significant difference of age between the non-ulcer and peptic ulcer subjects, whereas the male/female ratio and the $H$. pylori-positive rate were significantly higher in the peptic ulcer than in the non-ulcer subjects.
With respect to gastric mucosal atrophy, 43, 60, and 56 of the subjects were classified into the NA, MA, and SA groups, respectively. The mean age of the SA group was significantly higher than that of the NA group. The male/female ratio was also higher in the SA group than in the other groups. Regarding the $H$. pylori-positive rate, there were significant differences among the 3 groups ( $\mathrm{SA}>\mathrm{MA}>\mathrm{NA})$.

The frequencies of Nrf2 polymorphism and gastric mucosal changes. The results of electrophoresis using clinical samples are shown in Fig. 1. The -686-684 haplotypes and the -650 alleles were clearly separated. The frequency of each Nrf2 promoter polymorphism in our subjects is shown in Table III. Strong allelic associations were recognized among 3 polymorphisms [estimated D' $=1,0.95$, and 1 for $\operatorname{SNP}(-686)$ and SNP(-684), SNP(-686) and SNP(-650), and SNP(-684) and SNP(-650), respectively]. Since a strong allelic association 
Table III. The frequencies of genotypes.

\begin{tabular}{|c|c|c|c|c|c|c|c|c|}
\hline \multirow[t]{2}{*}{ Position } & & \multicolumn{4}{|c|}{ Genotype } & \multirow[t]{2}{*}{ OR } & \multirow[t]{2}{*}{$95 \% \mathrm{CI}$} & \multirow[t]{2}{*}{$\mathrm{p}$ value } \\
\hline & & $\mathrm{G} / \mathrm{G}$ & $\mathrm{G} / \mathrm{A}$ & $\mathrm{A} / \mathrm{A}$ & $\mathrm{A}$ allele $(\%)$ & & & \\
\hline \multirow[t]{6}{*}{-686} & Total & 53 & 71 & 29 & 42.2 & & & \\
\hline & Non-ulcer & 29 & 36 & 20 & 44.7 & reference & & \\
\hline & Peptic ulcer & 24 & 35 & 9 & 39.0 & 1.049 & $0.634-1.735$ & 0.85 \\
\hline & NA & 12 & 18 & 10 & 47.5 & reference & & \\
\hline & MA & 20 & 26 & 12 & 43.1 & & & \\
\hline & SA & 21 & 27 & 7 & 37.3 & 1.370 & 0.404-4.649 & 0.61 \\
\hline-684 & Total & 141 & 12 & 0 & 3.9 & & & \\
\hline \multirow[t]{6}{*}{-650} & Total & 86 & 68 & 5 & 24.5 & & & \\
\hline & Non-ulcer & 47 & 38 & 5 & 26.7 & reference & & \\
\hline & Peptic ulcer & 39 & 30 & 0 & 21.7 & 1.196 & $0.629-2.273$ & 0.58 \\
\hline & NA & 21 & 20 & 2 & 27.9 & reference & & \\
\hline & MA & 34 & 23 & 3 & 24.2 & & & \\
\hline & SA & 31 & 25 & 0 & 22.3 & 2.250 & $0.521-9.705$ & 0.28 \\
\hline
\end{tabular}

There were no significant differences between all genotypes. Allelic associations were seen among three polymorphisms $\left(\mathrm{D}^{\prime}=1,0.95\right.$, and 1; -686:-684, -686:-650, and -684:-650, respectively).

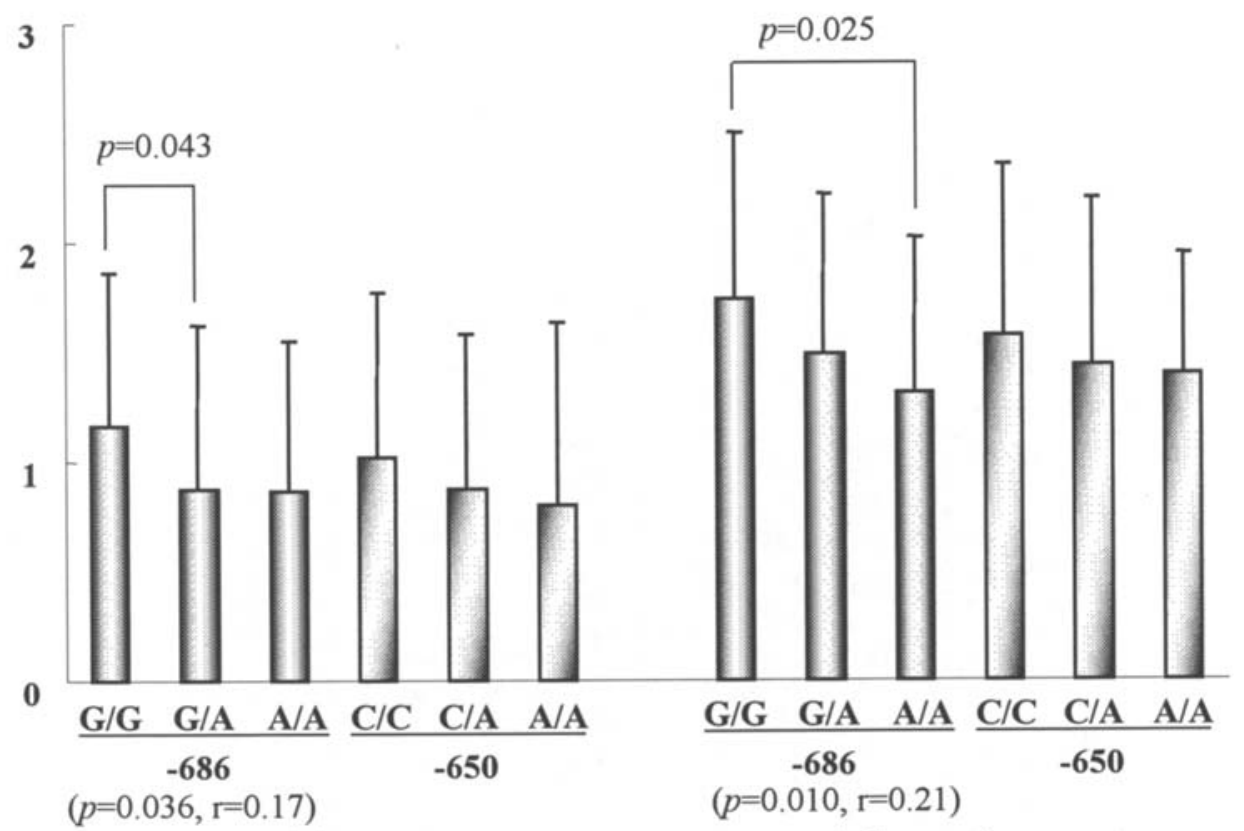

activity score

inflammation score

Figure 2. The association between SNP(-686) or (-650) and the activity or inflammation score. The comparison among two groups was performed by the Mann-Whitney U test and the associations between SNP(-686) and each score were assessed by linear regression analysis using the number of -686G alleles as a covariate.

was seen between SNP(-686) and SNP(-684), and the -684 A allele was quite rare, the association between the diseases and -684 polymorphism was not analyzed. Although the frequencies of $\operatorname{SNP}(-686)$ and $\operatorname{SNP}(-650)$ A alleles were decreased in the subjects with peptic ulcers or severe mucosal atrophy, no significant differences were seen.
Nrf2 polymorphism and inflammatory cell infiltration. The associations between SNP(-686) or SNP(-650) and the activity and inflammation scores are shown in Fig. 2. Using the number of $\mathrm{G}$ alleles as the covariate, both the activity and inflammation scores were significantly correlated with SNP(-686) positivity by linear regression analysis. 
Table IV. Interaction between H. pylori infection and SNP(-686) or SNP(-650).

\begin{tabular}{|c|c|c|c|c|c|c|}
\hline & \multicolumn{3}{|c|}{-686} & \multicolumn{3}{|c|}{-650} \\
\hline & $\mathrm{G} / \mathrm{G}$ & $\mathrm{G} / \mathrm{A}$ & $\mathrm{A} / \mathrm{A}$ & $\mathrm{C} / \mathrm{C}$ & $\mathrm{C} / \mathrm{A}$ & $\mathrm{A} / \mathrm{A}$ \\
\hline \multicolumn{7}{|c|}{ Activity score } \\
\hline 0 & $7(2)$ & $24(10)$ & $9(1)$ & $20(6)$ & $22(8)$ & $2(0)$ \\
\hline 1 & $32(29)$ & $33(30)$ & $15(11)$ & $47(42)$ & 33 (29) & $2(1)$ \\
\hline 2 & $12(12)$ & $13(12)$ & $5(3)$ & $16(15)$ & $13(12)$ & $1(0)$ \\
\hline 3 & $2(2)$ & $1(1)$ & 0 & $3(3)$ & 0 & 0 \\
\hline \multicolumn{7}{|c|}{ Inflammation score } \\
\hline 0 & $4(0)$ & $8(0)$ & $4(0)$ & $9(1)$ & $9(0)$ & 0 \\
\hline 1 & $12(8)$ & $22(15)$ & $12(4)$ & $25(14)$ & $22(14)$ & $3(1)$ \\
\hline 2 & $31(31)$ & $39(36)$ & $13(11)$ & $46(45)$ & $35(33)$ & $2(0)$ \\
\hline 3 & $6(6)$ & $2(2)$ & 0 & $6(6)$ & $2(2)$ & 0 \\
\hline
\end{tabular}

( ); . pylori-infected patient number. Activity score: $\mathrm{SNP}(-686), \mathrm{p}=0.385 ; \mathrm{HP}(+), \mathbf{p}=\mathbf{0 . 0 1 4} ; \mathrm{SNP}(-686) * \mathrm{HP}(+), \mathrm{p}=0.135 ; \mathrm{SNP}(-650), \mathrm{p}=0.470$; $\mathrm{HP}(+), \mathbf{p}=\mathbf{0 . 0 1 5}$; $\mathrm{SNP}(-650) * \mathrm{HP}(+), \mathrm{p}=0.664$. Inflammation score: $\mathrm{SNP}(-686), \mathrm{p}=0.164 ; \mathrm{HP}(+), \mathbf{p}<\mathbf{0 . 0 0 0 1} ; \mathrm{SNP}(-686) * \mathrm{HP}(+), \mathbf{p}=\mathbf{0 . 0 3 7}$; $\mathrm{SNP}(-650), \mathbf{p = 0 . 0 2 1} ; \mathrm{HP}(+), \mathbf{p = 0 . 0 0 9} ; \mathrm{SNP}(-650) * \mathrm{HP}(+), \mathbf{p = 0 . 0 4 1}$.

Table IV shows the distributions of $\operatorname{SNP}(-686)$ and SNP(-650) in patients with or without $H$. pylori infection for each activity and inflammation score. $H$. pylori infection showed a significant independent association with higher activity and inflammation scores by ANOVA or ANCOVA. An increase in the inflammation score and $\operatorname{SNP}(-650)$ also showed a significant independent relation. In addition, there was a significant interaction between $\mathrm{SNP}(-650)$ and $H$. pylori infection in relation to an increase in the inflammation score by ANOVA. SNP(-686) did not show an independent association, but an interaction with $H$. pylori infection was also recognized in relation to an increase in the inflammation score by ANCOVA using the number of $\mathrm{G}$ alleles as covariate. On the other hand, there was no significant relationship between any of these SNPs and an increase in the activity score.

\section{Discussion}

In this study, we investigated the relationship between three Nrf2 polymorphisms (all genotypes of which were in the Hardy-Weinberg equilibrium) and chronic gastritis. The subjects were patients with upper gastroesophageal symptoms who underwent gastroduodenal endoscopy. Among the participants, $37.8 \%$ had moderate gastric mucosal atrophy and $31.4 \%$ had severe atrophy. The overall $H$. pylori-positive rate of these subjects was comparatively high (73.0\%). A previous study demonstrated that the A allele frequencies for SNPs at position $-686,-684$, and -650 were $42.6 \%, 4.3 \%$, and $31.5 \%$, respectively. The reason why we observed a comparatively lower SNP(-650) A allele frequency may be that this study was not performed in a healthy population.

There have been few previous studies of the human Nrf2 gene, despite many reports on studies performed using rodents or in vitro. Therefore, it has not been clarified how polymorphisms influence the activity and expression of Nrf2, and we also obtained no evidence. However, it has been demonstrated that Nrf2-deficient mice display various pathological features, some of which are similar or related to human disorders (25-28). In addition, Nrf2 is reported to be an important regulator of genes induced by oxidative stress (19). Thus, there is no doubt that Nrf2 plays an important role in the elimination of ROS. In C57BL/6J mice, a strain sensitive to hyperoxic stress, an SNP was detected in the promoter region of the Nrf2 gene (21). Although there has only been one report of an association between the Nrf2 -650 $\mathrm{C} / \mathrm{C}$ genotype and chronic obstructive pulmonary disease in humans ( $\mathrm{p}=0.089)$ (23), Nrf2 promoter polymorphisms may influence inflammatory diseases by altering the activity of the gene product.

We excluded SNP(-684) from analysis because of the low allele frequency of this polymorphism and its very strong allelic association $\left(D^{\prime}=1,-686\right.$ and -684$)$. In $-650 \mathrm{C} / \mathrm{C}$ carriers, we observed an increase in mononuclear cells infiltrating the gastric mucosa. In addition, neutrophil activity and the infiltration of mononuclear cells were correlated with the number of $-686 \mathrm{G}$ alleles. Interactions between $H$. pylori infection and the $-650 \mathrm{C} / \mathrm{C}$ genotype or the number of $-686 \mathrm{G}$ alleles with mononuclear cell infiltration were also observed. There was a strong allelic association between positions -686 and $-650\left(D^{\prime}=0.95\right)$, so that $97 \%$ of $-686 \mathrm{G}$ was estimated to be $-650 \mathrm{C}$. Therefore, the investigation of the relationship between chronic gastritis and the G-C haplotype (-686--650) may clarify the importance of $\mathrm{Nrf} 2$.

There were no significant associations between Nrf2 polymorphism and gastric mucosal atrophy or metaplasia, although there was a significant relation between these polymorphisms and inflammatory cell infiltration. Factors released by inflammatory cells may be involved in the development of gastric mucosal atrophy or metaplasia. However, since gastritis can occur without atrophy or metaplasia in patients with marked inflammatory cell infiltration, the development of mucosal atrophy or metaplasia seems to be influenced by various factors, such as regulating 
tissue remodeling or cell differentiation. Thus, Nrf2 polymorphism may be associated with the promotion of inflammatory cell infiltration, but additional factors may be needed to cause mucosal atrophy or metaplasia.

H. pylori infection is a powerful pathogenic factor and was also a significant risk factor for an increase in the updated Sydney system scores in our study. Since an interaction between $H$. pylori infection and Nrf2 polymorphism was noted in relation to inflammatory cell infiltration, Nrf2 may generally influence inflammation in the stomach.

In conclusion, the number of $-686 \mathrm{G}$ alleles was correlated with neutrophil activity and mononuclear cell infiltration, and the $-650 \mathrm{C} / \mathrm{C}$ genotype was an independent risk factor for the mononuclear cell infiltration. In addition, both of these factors interacted with $H$. pylori infection to promote the infiltration of mononuclear cells. Thus, Nrf2 promoter polymorphisms are significantly associated with the development of gastric mucosal inflammation, either independently or by interacting with $H$. pylori infection.

\section{References}

1. Suerbaum S and Michetti P: Helicobacter pylori infection. N Engl J Med 347: 1175-1186, 2002.

2. Covacci A, Telford JL, Del GG, et al: Helicobacter pylori virulence and genetic geography. Science 284: 1328-1333, 1999.

3. Uemura N, Okamoto S, Yamamoto S, et al: Helicobacter pylori infection and development of gastric cancer. N Engl J Med 345: 784-789, 2001.

4. Emst PB and Gold BD: The disease spectrum of Helicobacter pylori: the immunopathogenesis of gastroduodenal ulcer and gastric cancer. Annu Rev Microbiol 54: 615-640, 2000.

5. Shimoyama T and Crabtree JE: Bacterial factors and immune pathogenesis in Helicobacter pylori infection. Gut 43 (suppl 1): 2-5, 1998 .

6. Bodger K and Crabtree JE: Helicobacter pylori and gastric inflammation. Br Med Bull 54: 139-150, 1998.

7. Yamaoka Y, Kita M, Kodama T, et al: Induction of various cytokines and development of severe mucosal inflammation by CagA positive Helicobacter pylori strains. Gut 41: 442-451, 1997.

8. Rad R, Gerhard M, Lang R, et al: The Helicobacter pylori blood group antigen-binding adhesion facilitates bacterial colonization and augments a nonspecific immune response. J Immunol 168: 3033-3041, 2002.

9. Shibata J, Goto H, Arisawa T, et al: Regulation of tumour necrosis factor (TNF) induced apoptosis by soluble TNF receptors in Helicobacter pylori infection. Gut 45: 24-31, 1999.

10. Bidwell J, Keen L, Gallagher G, et al: Cytokine gene polymorphism in human disease: on-line databases. Genes Immun 1: 3-19, 1999.
11. Hurme M, Lahdenpohja N and Santtila S: Gene polymorphisms of interleukins 1 and 10 in infectious and autoimmune diseases. Ann Med 30: 469-473, 1998.

12. Rad R, Prinz C, Neu B, et al: Synergistic effect of Helicobacter pylori virulence factors and interleukin-1 polymorphisms for the development of severe histological changes in the gastric mucosa. J Infect Dis 188: 272-281, 2003.

13. Rad R, Dossumbekova A, Neu B, et al: Cytokine gene polymorphisms influence mucosal cytokine expression, gastric inflammation, and host specific colonization during Helicobacter pylori infection. Gut 53: 1082-1089, 2004.

14. Fei BY, Xia B, Deng CS, et al: Association of tumor necrosis factor genetic polymorphism with chronic atrophic gastritis and gastric adenocarcinoma in Chinese Han population. World J Gastroenterol 10: 1256-1261, 2004.

15. Naito Y and Yoshikawa T: Molecular and cellular mechanisms involved in Helicobacter pylori-induced inflammation and oxidative stress. Free Radic Biol Med 33: 323-336, 2002.

16. Burdon RH: Superoxide and hydrogen peroxide in relation to mammalian cell proliferation. Free Radic Biol Med 18: 775-794, 1995.

17. Suzuki H, Miura S, Imaeda H, et al: Enhanced levels of chemiluminescence and platelet activating factor in ureasepositive gastric ulcer. Free Radic Biol Med 20: 449-454, 1996.

18. Davies GR, Simmonds NJ, Stevens TRJ, et al: Helicobacter pylori stimulates antral mucosal reactive oxygen metabolite production in vivo. Gut 35: 179-185, 1994.

19. Ishii $\mathrm{T}$, Itoh $\mathrm{K}$, Takahashi $\mathrm{S}$, et al: Transcription factor Nrf2 coordinately regulates a group of oxidative stress-inducible genes in macrophages. J Biol Chem 275: 16023-16029, 2000.

20. Cho HY, Jedlicka AE, Reddy SP, Zhang LY, Kensler TW and Kleeberger SR: Linkage analysis of susceptibility to hyperoxia. Nrf2 is a candidate gene. Am J Respir Cell Mol Biol 26: 42-51, 2002.

21. Cho HY, Jedlicka AE, Reddy SP, et al: Role of NRF2 in protection against hyperoxic lung injury in mice. Am J Respir Cell Mol Biol 26: 175-182, 2002.

22. Hirayama A, Yoh K, Nagase S, et al: EPR imaging of reducing activity in Nrf2 transcription factor-deficient mice. Free Radic Biol Med 34: 1236-1242, 2003.

23. Yamamoto T, Yoh K, Kobayashi A, et al: Identification of polymorphisms in the promoter region of the human NRF2 gene. Biochem Biophys Res Commun 321: 72-79, 2004.

24. Dixon MF, Genta RM, Yardley JH and Correa P: Classification and grading of gastritis: the updated Sydney system. Am J Surg Pathol 20: 1161-1181, 1996.

25. Chan K and Kan YW: Nrf2 is essential for protection against acute pulmonary injury in mice. Proc Natl Acad Sci USA 96: 12731-12736, 1999 .

26. Enomoto A, Itoh K, Nagayoshi E, et al: High sensitivity of Nrf2 knockout mice to acetaminophen hepatotoxicity associated with decreased expression of ARE-regulated drug metabolizing enzymes and antioxidant genes. Toxicol Sci 59: 169-177, 2001.

27. Aoki Y, Sato H, Nishimura N, Takahashi S, Itoh K and Yamamoto M: Accelerated DNA adduct formation in the lung of the Nrf2 knockout mouse exposed to diesel exhaust. Toxicol Appl Pharmacol 173: 154-160, 2001.

28. Ramos-Gomez M, Kwak MK, Dolan PM, et al: Sensitivity to carcinogenesis is increased and chemoprotective efficacy of enzyme inducers is lost in nrf2 transcription factor-deficient mice. Proc Natl Acad Sci USA 98: 3410-3415, 2001. 